\title{
Pediatricians' Knowledges, Attitudes, and Practices on Parafunctional Oral Habits and Orthodontic Problems in Children
}

\author{
Eda Arat Maden ${ }^{1}$, Ibrahim Eker ${ }^{2}$ \\ ${ }^{1}$ Department of Pediatric Dentistry, Center of Oral and Dental Health, Taksim Training and Research Hospital, Istanbul, Turkey. \\ ${ }^{2}$ Department of Pediatric Hematology, Afyon Kocatepe University Faculty of Medicine, Afyon, Turkey. \\ Correspondence Author: Eda Arat Maden \\ E-mail: edamaden1980@gmail.com \\ Received: $14.07 .2021 \quad$ Accepted: 16.09 .2021
}

\begin{abstract}
Objective: Treatment of dentofacial deformities via orthodontics can improve the health of the teeth and the gums and also numerous malpositioned teeth and jaws, and increase the quality of life in children affected by a malocclusion. The purpose of this research was to examine if pediatricians referred their patients to pediatric dentists, if they had sufficient knowledge and awareness in parafunctional habits and basic orthodontic principles, and if they examined their patients for parafunctional habits and malocclusions.

Methods: A descriptive, cross-sectional survey was sent to a sample of pediatricians in Turkey. The questionnaire consisted of 42 questions in five domains. A total of 166 pediatricians participated in the survey.

Results: In terms of the examination of the oral cavity, a low frequency of examination for the malocclusion (28.9\%) and oral functional habits (43.4\%) was detected. The reasons pediatricians referred patients to dentists varied from over-bite (24\%) to crowding (87\%). In the Chi-Square Test for the effect of the location of practice, the duration of practice, training about parafunctional oral habits, and orthodontic problems, patients examined per day on knowledge, attitude, and practices of pediatricians regarding orthodontic problems and parafunctional oral habits in children, significant relations were detected $(p<0.05)$.

Conclusion: Although the majority of the participants were aware that pediatricians have an important place in the prevention of parafunctional oral habits and orthodontic anomalies, they did not have the pertinent knowledge and practice to apply a complete and systematic examination for parafunctional oral habits and malocclusion.
\end{abstract}

Keywords: children, malocclusion, pediatricians, perception, referral.

\section{INTRODUCTION}

In dentistry, malocclusion is a healthcare issue considered deeply. It is also the third most prevalent oral disease and is described as a condition associated with abnormal relations between the teeth or dentition in any of the dimensions. Malocclusion, which may cause dental caries, periodontal disease, and increased possible temporomandibular disease, is considered a public health problem (1). Dentofacial appearance has a significant impact on individuals, especially children $(2,3)$. Shaw et al. reported that children were teased about their dentition more than any other factors (4). Malocclusion may therefore affect the individual's quality of life and self-esteem (3). Thus, a referral may significantly and positively change an individual's life. Early intervention performs the same function as interceptive orthodontics and prevents or reduces progression to fully developed malocclusion later in life and also excludes factors that inhibit the regular development of dental arches (5). Furthermore, early orthodontic treatment has been found to improve both psychosocial development and masticatory function in children. Posterior crossbites that prevent function, anterior crossbites resulting in traumatic occlusion and damage to the lower anterior teeth, anterior open bites that cause masticatory dysfunction as well as esthetic distress are some of the many indications for early treatment. In addition, prevention of trauma to the anterior teeth of individuals with severe Class II malocclusions with increased overjet is an indication for early orthodontic treatment $(6,7)$. Otherwise, people who receive orthodontic treatment can clean teeth more effectively. This might end up in decreased dental caries and periodontal diseases at significant levels (8).

Oral harmful habits include thumb or lip-sucking, bottlefeeding, tongue-thrusting, nail-biting, lip-biting, and mouthbreathing patterns, which have direct effects on the quality of life as they affect the stomatognathic systems (9). Previous authors argued that oral habits played significant roles in the development of dental anomalies and malocclusion 
if persisted beyond preschool age because they caused a disequilibrium between intra-and extra-oral muscular acts (10-12). These habits might cause poor dental health, be socially abasing, and avoid the development of speech clearance. For this reason, habits need a multidisciplinary approach for providing integral care for child patients. These habits need to be eliminated early using the appropriate protocols, including habit breakers to reduce the risk factors of developing malocclusions (13). There is a need for educating and increasing awareness of the pediatricians as well as teachers, children, parents about the harmful effects caused by such habits on the development of normal occlusion and the importance of timely intervention (14). The early treatment of orthodontic anomalies in the deciduous and early mixed dentition aims to prevent the development of significant anomalies in late mixed and permanent dentition to reduce or even eliminate the need for subsequent orthodontic treatment (15).

Pediatricians are pivotal in coordinating, collaborating, and communicating with interdisciplinary professionals to provide comprehensive care (16). Pediatricians are often the first healthcare professionals examining children in this respect. They are more likely to examine children earlier than pediatric dentists. Oral healthcare has an integral part of overall health. Therefore, they have a unique position in detecting and guiding oral and dental health diseases. They could serve as a good point of referring patients with malocclusion and parafunctional habits. Pediatricians may help in the early diagnosis of orthodontic issues, which might advance the treatment effect and its constancy over the years $(17,18)$.

Cooperation between pediatricians and pediatric dentists is essential for the continuity of general health and oral health (19). For this reason, it is important that pediatricians perform the first orthodontic examinations to diagnose abnormalities early and refer the patients consequently. As fas as we are concerned, there is only one study published worldwide conducted by Koufatzidou et al. (20) focusing on the assessment of awareness, knowledge, attitude, and practices of pediatricians on orthodontic problems and parafunctional habits in children.

The purpose of this research is to investigate the knowledge, attitudes, and practices of pediatricians who work in Turkey, concerning the prevention of parafunctional oral habits and malocclusion, and to raise awareness regarding the importance of pediatricians in preventing orthodontic problems in children.

\section{METHODS}

This report is based on a questionnaire conducted among Turkish pediatricians including those with post-graduation levels, working in government, private, and other healthcare sectors. Ethical permission required for the study to be carried out was obtained from Gaziosmanpaşa Training and
Research Hospital, Medical Research Local Ethics Board (Ethical board date/number: 26.05.2021/256).

The questionnaire used in our study consists of five chapters containing questions about the sociodemographic information of the participants, the risk factors of malocclusion, the evaluation of the attitudes of pediatricians towards the prevention of malocclusions and parafunctional habits, the evaluation of the behaviors of pediatricians on the examination and treatment of malocclusion and parafunctional habits, and the evaluation of knowledge levels and sources of information on malocclusion and parafunctional habits of pediatricians. The first section of questionnaire included sociodemographic data such as age, gender, title, institution where the specialty training was obtained, years of clinical experience, hours of patient care per week, and the number of patients seen per day. The second part included questions measuring the level of knowledge of pediatricians about risk factors related to malocclusion. In the third and fourth sections, physicians were asked about the attitudes and practices regarding the prevention of malocclusion and orthodontic examination practices (knowledge about orthodontic problems, whether they have performed orthodontic examinations, ways of referring patients to pediatric dentists); and in the fifth part, it was questioned if pediatricians received training on parafunctional oral habits and prevention of malocclusion and the source of their knowledge.

Google forms were used to create the questionnaire. Before starting the study, to test the comprehensibility and consistency of the questionnaire within the scope of the study, the questions were sent to 5 experts, 2 pediatric dentists, 2 pediatricians, and 1 biostatistician. Therefore, biased and confusing questions were omitted. A pilot study was performed before uploading the questionnaires online, to assess the appropriateness and clarity of the questions. The pilot study sample included participants representing ten pediatricians, and each received a hard copy of the questionnaire. The links to questionnaires were sent to pediatricians in Turkey by email, WhatsApp, and private social network platforms starting May 28, 2021, and the questionnaires were closed on June 18, 2021. A brief introduction was presented at the beginning of the survey to inform the respondents of the purpose and content of this study, and electronic informed consent was obtained if they agreed to complete the questionnaire. The minimum required respondents were predicted to be 160, with an estimated margin of error of $5 \%$ and $80 \%$ sample power in the OpenEpi power analysis program. A total of 166 Turkish pediatricians, all volunteers, answered the questionnaire.

\subsection{Statistical Analyses}

The statistical evaluations were made by using the SPSS (ver. 22.0. Chicago. II. USA) program. The relationship between pediatricians' age, gender, work sector, years of experience, patients per day, subspecialty, orthodontic treatment in children and relatives, training about parafunctional oral habits 
and orthodontic problems, and the knowledge, attitude, and practices of pediatricians regarding orthodontic problems and parafunctional oral habits in children were determined by the Chi-Square Test. Percentage frequencies were used in descriptive statistics. The significance level was accepted as $p<0.05$.

\section{RESULTS}

The number of participants agreeing to take part and completed the forms was 166 (43.4\% female, and 56.6\% males; 30.1\% subspecialists in pediatrics, and $69.9 \%$ non - subspecialists in pediatrics). The fields of participants in the pediatrics subspecialty are as follows; endocrine, pediatric neurology, pediatric cardiology, hematology, neonatology, allergy, gastroenterology, emergency, newborn, pediatric genetics, pediatric infection, pediatric pulmonology, social pediatrics. According to the duration of practice, $64.5 \%$ reported experience of more than 10 years, and $48.8 \%$ said they were working in a state hospital. Many reported working duration up to 40 hours a week (86.1\%). Various sociodemographic details of the study participants are available in Table 1.

Table 1. Socio-demographic characteristics of respondents

\begin{tabular}{|l|c|}
\hline Gender & $72(43.4)$ \\
\hline Male & $94(56.6)$ \\
\hline Female & $10(6)$ \\
\hline Age & $107(64.5)$ \\
\hline $20-30$ & $37(22.3)$ \\
\hline $31-40$ & $12(7.2)$ \\
\hline $41-50$ & \\
\hline 50 & $116(69.9)$ \\
\hline Subspecialty & $50(30.1)$ \\
\hline $\begin{array}{l}\text { No } \\
\text { Yes }\end{array}$ & \\
\hline Location of Practice & $81(48.8)$ \\
\hline Government Hosp. & $28(16.9)$ \\
\hline Private Hosp. & $54(32.5)$ \\
\hline University & \\
\hline Years at work & $59(35.5)$ \\
\hline $0-9$ & $79(47.6)$ \\
\hline $10-19$ & $28(16.9)$ \\
\hline$>19$ & $72(43.4)$ \\
\hline Hours per week & $143(87.2)$ \\
\hline$<40$ & $18(10.9)$ \\
\hline$>=40$ & $24(14.5)$ \\
\hline Patients per day & $30(18.2)$ \\
\hline$<=10$ & $93(56.4)$ \\
\hline $11-20$ & \\
\hline $21-30$ & \\
$>30$ & \\
\hline
\end{tabular}

Of the total sampling, $71.7 \%$ knew the risk factors of malocclusion. However, a deficiency of knowledge was found on the argument that the severity of ankyloglossia increases and the likelihood of malocclusion increases (45.2\%). However, more than half of the sample, $86.1 \%$ had sufficient knowledge regarding that long-term feeding of breast milk or formula with a bottle increases the likelihood of parafunctional oral habit and malocclusion. Similarly, $81.5 \%$ of the participants had sufficient knowledge regarding that if the duration of pacifier use is prolonged, the possibility of open-bite increases. For the knowledge regarding the probability of occurrence of malocclusion in children, $72.3 \%$ of the participants were aware of the effect of parafunctional oral habits. Moreover, $54.4 \%$ of the participants knew that premature and low birth weight increases the susceptibility to malocclusion by affecting tongue functions in children. Similarly, 54.4\% were knowledgeable regarding that breastfeeding for longer than 6 months reduces the possibility of malocclusion; and $71.7 \%$ of the participants answered the question that supporting healthy chewing function in early childhood can help to prevent malocclusion correctly. For the possibility of malocclusion in children with snoring and respiratory problems (mouth breathing), $71.7 \%$ of the participants answered this question correctly. Regarding pediatricians' knowledge levels about various orthodontic problems, knowledge of diastema was the most (80.1\%), while knowledge of overbite was the least (24.4\%) (Table 2).

Table 2. Pediatricians' knowledge levels about orthodontic problems and risk factors of malocclusion

\begin{tabular}{|c|c|c|}
\hline Question Response & & $\mathrm{n}(\%)$ \\
\hline $\begin{array}{l}\text { Children with parafunctional oral habits are more } \\
\text { likely to develop malocclusion. Do you have any } \\
\text { information about this? }\end{array}$ & $\begin{array}{l}\text { No } \\
\text { Yes }\end{array}$ & $\begin{array}{c}46(27.7) \\
120(72.3)\end{array}$ \\
\hline $\begin{array}{l}\text { Breastfeeding for longer than } 6 \text { months reduces } \\
\text { the likelihood of developing parafunctional } \\
\text { oral habits and malocclusion. Do you have any } \\
\text { information about this? }\end{array}$ & $\begin{array}{l}\text { No } \\
\text { Yes }\end{array}$ & $\begin{array}{l}74(44.6) \\
92(55.4)\end{array}$ \\
\hline $\begin{array}{l}\text { Long-term feeding of breast milk or formula with } \\
\text { a bottle increases the possibility of developing } \\
\text { parafunctional oral habits and malocclusion. Do } \\
\text { you have any information about this? }\end{array}$ & $\begin{array}{l}\text { No } \\
\text { Yes }\end{array}$ & $\begin{array}{c}22(13.3) \\
143(86.1)\end{array}$ \\
\hline $\begin{array}{l}\text { Preterm birth and low birth weight increase } \\
\text { susceptibility to malocclusion by affecting tongue } \\
\text { functions. Do you have any information about } \\
\text { this? }\end{array}$ & $\begin{array}{l}\text { No } \\
\text { Yes }\end{array}$ & $\begin{array}{l}74(44.6) \\
92(55.4)\end{array}$ \\
\hline $\begin{array}{l}\text { If the pacifier use time is prolonged, the } \\
\text { possibility of open-bite increases. Do you have } \\
\text { any information about this? }\end{array}$ & $\begin{array}{l}\text { No } \\
\text { Yes }\end{array}$ & $\begin{array}{c}30(18.1) \\
136(81.9)\end{array}$ \\
\hline $\begin{array}{l}\text { Children with snoring and breathing problems } \\
\text { (mouth breathing) are more prone to } \\
\text { malocclusion. Do you have any information } \\
\text { about this? }\end{array}$ & $\begin{array}{l}\text { No } \\
\text { Yes }\end{array}$ & $\begin{array}{c}46(27.7) \\
119(71.7)\end{array}$ \\
\hline $\begin{array}{l}\text { The higher the severity of the tongue ligament } \\
\text { (short, thick frenulum), the more likely it is } \\
\text { to develop malocclusion. Do you have any } \\
\text { information about this? }\end{array}$ & $\begin{array}{l}\text { No } \\
\text { Yes }\end{array}$ & $\begin{array}{l}75(45.2) \\
91(54.8)\end{array}$ \\
\hline $\begin{array}{l}\text { Supporting healthy chewing function in early } \\
\text { childhood can help prevent malocclusion. Do you } \\
\text { have any information about this? }\end{array}$ & $\begin{array}{l}\text { No } \\
\text { Yes }\end{array}$ & $\begin{array}{c}47(28.3) \\
119(71.7)\end{array}$ \\
\hline
\end{tabular}

A total of $91.6 \%$ believed that they played important roles in preventing malocclusion and parafunctional oral habits in 
children. Also, 97.0\% considered dental visits for preventing malocclusion and parafunctional oral habits. About the fact that pediatricians have to examine children's teeth and oral cavities, $92.8 \%$ of the participants responded positively. Moreover, when they were asked if the malocclusion can be prevented $91.0 \%$ of the participants replied positively (Table 3 ).

Table 3. Questions related to attitude domain among the pediatricians

\begin{tabular}{|l|c|c|}
\hline \multicolumn{3}{|c|}{ Question Response } \\
\hline The pediatricians have to examine the oral cavity. & No & $12(7.2)$ \\
Yes & $154(92.8)$ \\
\hline $\begin{array}{l}\text { Dental examination is important in the prevention of } \\
\text { malocclusion and parafunctional oral habits. }\end{array}$ & No & $5(3)$ \\
Yes & $161(97)$ \\
\hline Malocclusion can be prevented. & No & $22(13.3)$ \\
\hline $\begin{array}{l}\text { Pediatricians play an important role in the prevention } \\
\text { of malocclusion and parafunctional oral habits in } \\
\text { children. }\end{array}$ & No & $143(86.1)$ \\
\hline
\end{tabular}

They were also asked if they evaluated the oral functional habits of their patients. While $41.6 \%$ of the sample indicated that they evaluated when the patient had a complaint about this subject, $43.4 \%$ of the sample indicated that they evaluated every time. Only $28.9 \%$ of the participants reported performing routine oral examinations for malocclusion. Participants were asked regarding the time for the child for the first oral health examination. A total of $30.1 \%$ of the sample indicated that they counseled the first oral health examination when the child was 0-2 years old. Moreover, when they were asked regarding how often an oral health examination was recommended, only $49.4 \%$ of the participants indicated it as six months. Moreover, participants were asked if they would refer a child to pediatric dentists when they identified a child with malocclusion or any parafunctional habits. Most of the sample (97.6\%) indicated that they would refer. The type of referral was mostly advising parents/guardians to go to a pediatric dentist (80.1\%). The answer to the question when your patient, whom you referred to a pediatric dentist, comes to you for a check, do you check whether a pediatric dentist examination has been done was mostly "Yes" (75.9\%) (Table 4). Their answers for the reasons for referral due to orthodontic problems to pediatric dentists differed for each condition from $24 \%$ for over-bite to $87 \%$ for crowding. On the other hand, their answers for the reasons for referral due to parafunctional oral habits and developmental anomalies to pediatric dentists differed for each condition from $5.3 \%$ for nail-biting to $38.4 \%$ for prolonged use of pacifiers. On the other hand, prolonged use of pacifiers was the most common reason for referral due to parafunctional oral habits and high labial frenulum attachment was the most common reason for referral to (38.5\%) due to developmental anomalies.

The overall good scores of the knowledge, attitudes and practices with a combined overall score in which a discrepancy was detected between the knowledge, attitudes, and practices of the participants are given in Table 5. Many participants had a high percentage of good attitudes (94.0\%) when compared with good knowledge $(71.2 \%)$ and good practice (61.2\%) (having good practice was the least). No significant differences were detected between females and males in terms of knowledge, attitudes, and practices ( $p>0.05$ ). In the distribution of good practice, it was seen that the highest rate was among those working in private hospitals, and the lowest rate was among those working in state hospitals. When the distribution of good combination scores was compared according to years of experience, it was found that dental professionals who had $>19$ duration of practice had the highest level of good combination scores. Good knowledge, good practice, and good combination scores respectively $87.8 \%$, $78.0 \%, 100 \%$ were found to be statistically significantly higher in those who received training about parafunctional oral habits and orthodontic problems than those who did not. On the other hand, good practice scores of dental professionals (76.2\%) who saw less than 20 patients a day were significantly higher than those who saw more than 20 (56.6\%).

Table 4. Questions related to practice domain among the pediatricians

\begin{tabular}{|c|c|c|}
\hline \multicolumn{2}{|r|}{ Question Response } & $\mathrm{n}(\%)$ \\
\hline $\begin{array}{l}\text { Do you evaluate the oral } \\
\text { functional habits of your } \\
\text { patients? }\end{array}$ & $\begin{array}{l}\text { No } \\
\text { If any problem } \\
\text { Yes }\end{array}$ & $\begin{array}{l}25(15.1) \\
69(41.6) \\
72(43.4)\end{array}$ \\
\hline $\begin{array}{l}\text { Do you perform oral health } \\
\text { examinations for malocclusion } \\
\text { for your patients? }\end{array}$ & $\begin{array}{c}\text { No } \\
\text { If any problem } \\
\text { Yes } \\
\end{array}$ & $\begin{array}{l}39(23.5) \\
79(47.6) \\
48(28.9) \\
\end{array}$ \\
\hline $\begin{array}{l}\text { When do you perform the first } \\
\text { oral health examination for } \\
\text { your patients? }\end{array}$ & $\begin{array}{c}\text { I don't } \\
\text { Immediately after birth } \\
0-2 \\
>=2\end{array}$ & $\begin{array}{c}13(7.8) \\
90(54.2) \\
50(30.1) \\
12(7.2) \\
\end{array}$ \\
\hline $\begin{array}{l}\text { When would you recommend } \\
\text { the first oral health } \\
\text { examination to your patients? }\end{array}$ & $\begin{array}{l}\text { Immediately after birth } \\
0-2 \\
>=2\end{array}$ & $\begin{array}{l}68(41.0) \\
80(48.2) \\
17(10.2)\end{array}$ \\
\hline $\begin{array}{l}\text { How often are you } \\
\text { recommended oral health } \\
\text { examination? }\end{array}$ & $\begin{array}{l}\text { If any problem } \\
\text { per } 6 \text { mo. } \\
\text { per one year }\end{array}$ & $\begin{array}{l}24(14.5) \\
82(49.4) \\
59(35.5) \\
\end{array}$ \\
\hline $\begin{array}{l}\text { Do you refer your patient to } \\
\text { a pediatric dentist when you } \\
\text { diagnose malocclusion or any } \\
\text { parafunctional oral habit? }\end{array}$ & $\begin{array}{l}\text { No } \\
\text { Yes }\end{array}$ & $\begin{array}{c}3(1.8) \\
162(97.6)\end{array}$ \\
\hline $\begin{array}{l}\text { If your answer to the previous } \\
\text { question is yes, how do you do } \\
\text { the referral? }\end{array}$ & $\begin{array}{l}\text { I advise families to go to a } \\
\text { pediatric dentist. } \\
\text { I refer the pediatric dentist } \\
\text { I work with by giving } \\
\text { information myself. } \\
\text { I consult the pediatric } \\
\text { dentist through the } \\
\text { system. }\end{array}$ & $\begin{array}{c}133(80.1) \\
12(7.2) \\
18(10.8)\end{array}$ \\
\hline $\begin{array}{l}\text { When your patient, whom } \\
\text { you referred to the pediatric } \\
\text { dentist, comes to you for } \\
\text { a check-up, do you check } \\
\text { whether the pediatric dentist } \\
\text { examination is performed? }\end{array}$ & $\begin{array}{l}\text { No } \\
\text { Yes }\end{array}$ & $\begin{array}{c}38(22.9) \\
126(75.9)\end{array}$ \\
\hline $\begin{array}{l}\text { Do you have any patients } \\
\text { you consult with pediatric } \\
\text { dentistry? }\end{array}$ & $\begin{array}{l}\text { No } \\
\text { Yes }\end{array}$ & $\begin{array}{l}67(40.4) \\
96(57.8) \\
\end{array}$ \\
\hline
\end{tabular}


The participants preferred several methods to receive dental education and training on parafunctional oral habits and orthodontic anomalies. Workshops and colleagues were the most preferred method, (99.4\%). Furthermore, previous dental training about orthodontic problems in children was reported by only $12.6 \%$ of participants. On the other hand, their responses for receiving dental education regarding orthodontic problems and protective measures in children during their medical or specialty training were mostly "I did not receive any dental education and training" (80.7\%). They were asked if there were any children among their children or relatives who received orthodontic treatment, and $59.6 \%$ of the sample indicated that there were. Most of the participants $(96.4 \%)$, indicated that they needed more knowledge about parafunctional oral habits and prevention of malocclusion (Table 6).

Table 5. Relationship of overall scores of each domain-knowledge, attitude, and practice, and combined to various factors

\begin{tabular}{|c|c|c|c|c|c|c|c|c|}
\hline & \multicolumn{2}{|c|}{ good knowledge } & \multirow{2}{*}{$\begin{array}{c}\text { good attitude } \\
\mathrm{n}(\%)\end{array}$} & \multirow[b]{2}{*}{$\mathrm{p}$} & \multirow{2}{*}{$\begin{array}{c}\text { good practice } \\
\mathrm{n}(\%)\end{array}$} & \multirow[b]{2}{*}{$p$} & \multicolumn{2}{|c|}{ good combination } \\
\hline & $n(\%)$ & $\mathrm{p}$ & & & & & $\mathrm{n}(\%)$ & $\mathrm{p}$ \\
\hline \multicolumn{9}{|l|}{ Gender } \\
\hline Male & $52(72,2)$ & \multirow{2}{*}{0,893} & $68(98,4)$ & \multirow{2}{*}{0,824} & $46(63,9)$ & \multirow{2}{*}{0,535} & $65(90,3)$ & \multirow{2}{*}{0,321} \\
\hline Female & $67(71,3)$ & & $88(93,6)$ & & $55(59,1)$ & & $80(85,1)$ & \\
\hline \multicolumn{9}{|l|}{ Work sector } \\
\hline State hospital & $60(74,1)$ & \multirow{3}{*}{$0,031^{*}$} & $74(91,4)$ & \multirow{3}{*}{0,415} & $38(47,5)$ & \multirow{3}{*}{$0,001 *$} & $68(84,0)$ & \multirow{3}{*}{0,08} \\
\hline Private hospital & $24(85,7)$ & & $27(96,4)$ & & $24(85,7)$ & & $28(100,0)$ & \\
\hline University & $32(59,3)$ & & $52(96,3)$ & & $36(66,7)$ & & $46(85,2)$ & \\
\hline \multicolumn{9}{|c|}{ Duration of practice } \\
\hline $0-9$ & $42(71,2)$ & \multirow{3}{*}{0,912} & $57(96,6)$ & \multirow{3}{*}{0,342} & $37(62,7)$ & \multirow{3}{*}{0,173} & $54(91,5$ & \multirow{3}{*}{$0,01^{*}$} \\
\hline $10-19$ & $56(70,9)$ & & $72(91,1)$ & & $43(55,1)$ & & $63(79,7)$ & \\
\hline$>19$ & $21(75,0)$ & & $27(96,4)$ & & $21(75,0)$ & & $28(100,0)$ & \\
\hline \multicolumn{9}{|l|}{ Subspecialty } \\
\hline Yes & $33(66,0)$ & \multirow{2}{*}{0,286} & $112(96,6)$ & \multirow{2}{*}{0,068} & $25(51,0)$ & \multirow{2}{*}{0,081} & $42(84,0)$ & \multirow{2}{*}{0,394} \\
\hline No & $86(74,1)$ & & $44(88,0)$ & & $76(65,5)$ & & $103(88,8)$ & \\
\hline \multicolumn{9}{|c|}{ Training about parafunctional oral habits and orthodontic problems } \\
\hline Yes & $36(87,8)$ & \multirow{2}{*}{$0,008^{*}$} & $40(97,6)$ & \multirow{2}{*}{0,454} & $32(78,0)$ & \multirow{2}{*}{$0,011^{*}$} & $41(100,0)$ & \multirow{2}{*}{$0,005^{*}$} \\
\hline No & $83(66,9)$ & & $116(92,8)$ & & $69(55,6)$ & & $104(83,2)$ & \\
\hline \multicolumn{9}{|c|}{ Orthodontic treatment in pediatricians' children and relatives } \\
\hline Yes & $70(70,7)$ & & $95(96,6)$ & 017 & $62(62,6)$ & & $90(90,9)$ & \\
\hline No & $47(72,3)$ & $0,0<J$ & $59(90,8)$ & $0,1 / 4$ & $37(57,8)$ & כנכ,ט & $53(81,5)$ & 0,013 \\
\hline Patients per day & & & & & & & & \\
\hline$<=20$ & $30(71,4)$ & & $40(95,2)$ & & $32(76,2)$ & * & $39(92,9)$ & \\
\hline$>20$ & $89(72,4)$ & $1, \cup \cup 0$ & $115(93,5)$ & 0,135 & $69(56,6)$ & $0,0<4$ & $106(86,2)$ & 0,232 \\
\hline
\end{tabular}

Chi-square test $\quad{ }^{*} p<0.05$

Table 6. Evaluation of training and education among the pediatrician

\begin{tabular}{|c|c|c|}
\hline & Variable Response & $n(\%)$ \\
\hline $\begin{array}{l}\text { I need more education and training about parafunctional oral habits and } \\
\text { malocclusion prevention. }\end{array}$ & $\begin{array}{l}\text { No } \\
\text { Yes }\end{array}$ & $\begin{array}{c}6(3.6) \\
160(96.4)\end{array}$ \\
\hline $\begin{array}{l}\text { Have you received any training on orthodontic problems in children and } \\
\text { the approaches to be applied? }\end{array}$ & $\begin{array}{l}\text { No } \\
\text { Yes, I got it in my medical school education. } \\
\text { Yes, I got it my specialist training. }\end{array}$ & $\begin{array}{c}134(80.7) \\
18(10.8) \\
3(1.8) \\
\end{array}$ \\
\hline $\begin{array}{l}\text { Have you received any training on parafunctional habits (bad oral habits) } \\
\text { and approaches to be applied in children? }\end{array}$ & $\begin{array}{l}\text { No } \\
\text { Yes, I got it in my medical school education. } \\
\text { Yes, I got it my specialist training. }\end{array}$ & $\begin{array}{c}125(75.3) \\
21(12.7) \\
20(12)\end{array}$ \\
\hline Do any of your children or relatives receive orthodontic treatment? & $\begin{array}{l}\text { No } \\
\text { Yes }\end{array}$ & $\begin{array}{l}65(39.2) \\
99(59.6)\end{array}$ \\
\hline
\end{tabular}




\section{DISCUSSION}

This research was conducted to emphasize the need to improve the relationship between the pediatrician and the pediatric dentists, and also to work on the areas that physicians need to improve their knowledge about orthodontic problems and to recognize the importance of pediatric dentistry. Orthodontic anomalies cause important global oral health issues, but parents do not take their children to the dentist for regular examination of orthodontic problems as early as they do with pediatricians; and therefore, pediatricians are considered credible and excellent sources to promote oral health and prevent malocclusion (21). However, our study showed a lack of knowledge and practice among pediatricians regarding parafunctional oral habits and orthodontic problems in children. The results of our study indicated a discrepancy between the practice, knowledge, and attitudes of participants whose practice score was lower (61.2\%) compared with attitude scores (94.0\%) and knowledge scores (71.2\%). The majority of the sample had admissible attitude levels on malocclusion and risk factors, but few of them reported oral health-related activities, which comply with the data of an American national survey of Lewis et al. (22). We could only identify one survey regarding pediatricians' awareness of orthodontic problems and related conditions in the literature (20). Since only one related previous study was found on this subject, we could only use this pre-existing survey/questionnaire as a valid source (20). According to the results of this previous survey with 96 pediatricians in Greece, the majority were aware of the importance of examination of the oral cavity, but they did not have appropriate knowledge for performing a full and systematic screening in terms oforthodontic problems. In this previous study, a low frequency was detected in the examination of the position of teeth (54\%) and jaws $(51 \%)$, which is in line with this study. Similarly, the results of this study show that physicians examine the oral cavity for malocclusion when the patient has a complaint about this subject $(47.6 \%)$. The reasons pediatricians referred patients to specialists varied from mouth breathing-snoring $24 \%(23 / 96)$ to face or teeth asymmetry $87 \%$ (84/96) (20). In this study, the reasons pediatricians referred patients to specialists varied from over-bite $24 \%$ to crowding $87 \%$.

However, we could also compare our results with studies that assessed pediatricians' practice, knowledge, and attitudes for oral health and dental caries (22-24). Some studies reported poor knowledge on oral health among pediatricians $(22,25,26)$ and studies from Turkey $(27)$, as well as in Canada (28), and some others reported contrary results $(22,29)$.

The knowledge and understanding of healthcare providers showed that approximately $55.4 \%$ of pediatricians could relate the importance of breastfeeding and oral health. Infants' oral muscles are exercised strenuously in suckling in breastfeeding, which is an important effect on the thrust and growth of the mandible (30).

Moreover, many participants (\%92.8) believed that pediatricians must examine the teeth of children as part of their daily practice. The study of Di Giuseppe et al. (31) reported that pediatricians (\%96.6) considered their roles in the examination of children's teeth. Most participants (\%91) considered their roles in children's teeth examination, but few of them reported evaluating children's oral functional habits (\%43.4) and the oral health examination for malocclusion (\%28.9). Similarly, Alshunaiber et al. (21) and Di Giuseppe et al. (31) reported a low percentage of pediatricians who performed oral health examinations for children. However, the study of Indira et al. (32) found better practice levels, and many pediatricians (\%98.9) reported that they included children's teeth examination in routine practice. Considering that pediatricians encounter pediatric patients earlier and more frequently and can play an important role in early diagnosis, it becomes clear that pediatricians in our country should be informed about parafunctional oral habits and orthodontic problems in children and encouraged.

While easily diagnosed conditions such as early loss of primary teeth and crowding in dentition resulted in high referral frequency, other anomalies were not common reasons for referral. Therefore, it might be considered that pediatricians have limited basic dental training, and this causes low confidence in oral cavity screening, recommendation, or consultation (21). A previous study found that many orthodontists recommended that the first assessment of occlusion must be done before the age of 7 , and crossbites must be preferably applied during primary and early-mixed dentition stages (33). Proper and timely evaluation of malocclusions and the associated factors with malocclusions in primary dentition might help to prevent and manage occlusion-related problems better in life.

In the present study, as in the study of Sezer et al. (27), lowlevel knowledge on some aspects of children's parafunctional oral habits and orthodontic problems together with the associated practice among pediatricians might be related to the lack of required dental training and education of the majority of participants. Also, decreased frequency in the practice of children's oral health-related activities among pediatricians who saw more than 20 patients a day and worked in state hospitals may be associated with a lack of clinical time for detailed examination.

In the present study, a significant portion of the participants (91\%) reported that pediatricians have important roles in preventing malocclusion and parafunctional oral habits. However, $96.4 \%$ of them stated that their knowledge level on the prevention of malocclusion and parafunctional oral habits is not sufficient and they need more information. This result reveals that pediatricians should be informed more about the subject both during and after medical education.

\section{Limitations}

The study has certain limitations. First of all, online selfassessment questionnaires may be affected by the difficulty of completing them. This could affect the validity of the data provided. In the questionnaire, it was asked whether 
the participants refer the patients to a pedodontist when orthodontic problems are the issues. However, some pediatricians might refer the patient to an orthodontist or even a dentist. But it doesn't mean that they don't guide the patient when they refer the patient to an orthodontist or dentist. This also might affect the results.

\section{CONCLUSION}

Malocclusion and parafunctional habits can negatively affect the quality of life, self-esteem, and health of the periodontium. Pediatricians have the potential to make a significant impact on their clients' oral health by identifying parafunctional habits and malocclusion early and making referrals. Establishing an oral and occlusal assessment during general health appointments reinforces comprehensive client care and provides greater opportunities for interprofessional collaboration. Understanding the etiology, risk factors, and impact of malocclusions will support pediatricians in making informed decisions and in achieving comprehensive personcentered care plans.

\section{Acknowledgments}

The authors thank all pediatricians for their participation in the study. We would also like to thank Yiğit Şenol who helped to perform statistical analysis.

\section{Funding}

No funding was received for this study.

\section{Conflict of interest}

The authors have no conflicts of interest to declare.

\section{REFERENCES}

[1] Alogaibi YA, Murshid ZA, Alsulimani FF. Prevalence of malocclusion and orthodontic treatment needs among young adults in Jeddah city. J Orthod Sci 2020;9:3.

[2] Proffit W. Contemporary orthodontics. 4th ed. St. Louis: Elsevier Mosby;2013.

[3] Roberts-Harry D, Sandy J. Orthodontics. Part 1: Who needs orthodontics? Br Dent J. 2003;195(8):433-437.

[4] Shaw WC, Meek SC, Jones DS. Nicknames, teasing, harassment and the salience of dental features among school children. $\mathrm{Br}$ J Orthod 1980;7(2):75-80.

[5] Tausche E, Luck O, Harzer W. Prevalence of malocclusions in the early mixed dentition and orthodontic treatment need. Eur J Orthod 2004;26(3):237-244.

[6] Koroluk LD, Tulloch JF, Phillips C. Incisor trauma and early treatment for class II division 1 malocclusion. Am J Orthod Dentofacial Orthop 2003;123(2):117-125.

[7] Artun J, Behbehani F, Al-Jame B, Kerosuo H. Incisor trauma in an adolescent Arab population: Prevalence, severity, and occlusal risk factors. Am J Orthod Dentofacial Orthop 2005;128(3):347-352.
[8] Kluemper GT, Beeman CS, Hicks EP. Early orthodontic treatment: What are the imperatives? J Am Dent Assoc 2000;131(5):613-620.

[9] Agurto PV, Diaz RM, Cadiz OD, Bobenrieth FK. Oral bad habits frequency and its association with dentomaxilar abnormal development, in children three to six year old in Santiago Oriente. Rev Chil Pediatr 1999;70:470-482.

[10] Grabber TM. Thumb and finger sucking. Am J Orthod 1959;45 259-264.

[11] Garde JB, Suryavanshi RK, Jawale BA, Deshmukh V, Dadhe DP, Suryavanshi MK. An epidemiological study to know the prevalence of deleterious oral habits among 6 to 12 year old children. J Int Oral Health 2014;6(1):39-43.

[12] Warren JJ, Bishara SE, Steinbock KL, Yonezu T, Nowak AJ. Effects of oral habits' duration on dental characteristics in the primary dentition. J Am Dent Assoc 2001; 132(12):1685-1693.

[13] Urzal V, Braga AC, Ferreira AP. The prevalence of anterior open bite in Portuguese children during deciduous and mixed dentition - Correlations for a prevention strategy. Int Orthod 2013;11(1):93-103.

[14] SDhull K, VermaT, Dutta B. Prevalence of Deleterious Oral Habits among 3 - to 5-year-old Preschool Children in Bhubaneswar, Odisha, India. Int J Clin Pediatr Dent 2018;11(3):210-213.

[15] Schopf P. Indication for and frequency of early orthodontic therapy or interceptive measures. J Orofac Orthop 2003;64(3):186-200.

[16] Schuster C. Orthodontic referral resource. RDHmag. Available from: www.rdhmag.com/articles/print/volume-30/issue-11/ features/ orthodontic-referral-resource.html

[17] Ovsenik M, Primozic J. How to push the limits in the transverse dimension? Facial asymmetry, palatal volume and tongue posture in children with unilateral posterior cross bite: a three-dimensional evaluation of early treatment. Orthod $\mathrm{Fr}$ 2014;85(2):139-149.

[18] Peiro AC. Interceptive orthodontics: The need for early diagnosis and treatment of posterior crossbites. Med Oral Patol Oral Cir Bucal. 2006; 11(2):E210-4.

[19] Özveren N, Batur Kara S, Yaman Şişman K, Baltacı E. Knowledge, attitude, training and practices of pediatricians in relation to the prevention of oral diseases in Thrace region. BSJ Health Sci 2021;4(2):52-57.

[20] Koufatzidou M, Koletsi D, Basdeki El, Pandis N, Polychronopoulou A. Pediatricians' awareness on orthodontic problems and related conditions-a national survey. Prog Orthod 2019;20(1):33.

[21] Alshunaiber R, Alzaid H, Meaigel S, Aldeeri A, Adlan A. Early childhood caries and infant's oral health; pediatricians' and family physicians' practice, knowledge and attitude in Riyadh city, Saudi Arabia. Saudi Dent J 2019;31(Suppl):96-105.

[22] Lewis CW, Boulter S, Keels MA, Kril DM, Mouradian WE, O'Connor KG, Quinonez RB. Oral health and Pediatricians: results of a national survey. Acad Pediatr 2009;9(6): 457-461.

[23] Brickhouse TH, Unke JH, Kacitis I, Best AM, Davis RD. Infant oral health care: a survey of general dentists, pediatric dentists and pediatricians in Virginia. Pediatr Dent 2008;30(2):147-153.

[24] Krol DM. Educating pediatricians on children's oral health: past, present, and future. Pediatrics 2004;113(5):e487-492.

[25] Long CM, Quinorez RB, Beil HA. Pediatricians' assessment of carries risk and need for a dental evaluation in preschool aged children. BMC Pediatr 2012;12:49. 
[26] Murthy GA, Mohandas U. The knowledge, attitude and practice in prevention of dental caries amongst pediatricians in Bangalore: A cross - sectional study. J Indian Soc Pedod Prev Dent 2010;28(2):100-103.

[27] Sezer RG, Paketci C, Bozaykut A. Paediatricians' awareness of children's oral health: knowledge, training, attitudes and practices among Turkish paediatricians. Pediatrics \& Child Health 2013;18(4):e15-19.

[28] Prakash P, Lawrence HP, Harvey BJ, Mclsaac WJ, Limeback $\mathrm{H}$, Leake JL. Early childhood caries and infant oral health: Paediatricians" and family physicians' knowledge, practices and training. Paediatr Child Health 2006;11(3):151-157.

[29] Shetty RM, Dixit UB. Paediatricians' views on dental and oral health and treatment needs in children. Oral Health Prev Dent 2011;9(4):315-322.
[30] Nammalwar RB, Rangeeth P. Knowledge and attitude of pediatricians and family physicians in Chennai on pediatric dentistry: A survey. Dent Res J (Isfahan) 2012;9(5):561-566.

[31] Di Giuseppe G, Nobile CG, Marinelli A, Angelillo IF. Knowledge, attitude and practices of pediatricians regarding the prevention of oral diseases in Italy. BMC Public Health 2006;6:176.

[32] Indira M, Dhull KS, Nandlal B. Knowledge, Attitude and Practice toward Infant Oral Healthcare among the Pediatricians of Mysore: A Questionnaire Survey.Int J Clin Pediatr Dent 2015;8(3):211-214.

[33] Pietilä I, Pietilä T, Pirttiniemi P, Varrela J, Alanen P. Orthodontists' views on indications for and timing of orthodontic treatment in Finnish public oral health care. Eur J Orthod 2008;30(1):4651.

How to cite this article: Arat Maden E, Eker I. Pediatricians' Knowledges, Attitudes, and Practices on Parafunctional Oral Habits and Orthodontic Problems in Children. Clin Exp Health Sci 2021; 11: 834-841. DOI: 10.33808/clinexphealthsci.971473 